Plas, A.G.M. van der, Onwuteaka-Philipsen, B.D., Francke, A.L., Jansen, W.J.J., Vissers, K.C., Deliens, L. Palliative care case managers in primary care: a descriptive study of referrals in relation to treatment aims. Journal of Palliative Medicine: 2015, 18(4), 324-331 nivel

\begin{tabular}{|l|l|}
\hline $\begin{array}{l}\text { Postprint } \\
\text { Version }\end{array}$ & 1.0 \\
\hline Journal website & http://dx.doi.org/10.1089/jpm.2014.0269 \\
\hline Pubmed link & $\underline{\text { http://www.ncbi.nlm.nih.gov/pubmed/25495143 }}$ \\
\hline DOI & $10.1089 / j p m .2014 .0269$ \\
\hline
\end{tabular}

This is a NIVEL certified Post Print, more info at http://www.nivel.eu

\title{
Palliative Care Case Managers in Primary Care: A Descriptive Study of Referrals in Relation to Treatment Aims
}

ANNICKA G. M. VAN DER Plas, MA, ${ }^{1,2,3}$ PROF. DR. BREgJe D. ONWUTEAKA-PhILIPSEN, ${ }^{1,2,3}$ Prof. DR. ANNEKE L. FrANCKE, ${ }^{1,2,3,4}$ WiM J. J. JANSEN, MSC, ${ }^{2,5}$ PROF. DR. KRIS C. VisSERS, ${ }^{6}$ AND PROF. DR. LUC DELIENS ${ }^{7}$

${ }^{1}$ Department of Public and Occupational Health, VU University Medical Center, Amsterdam, the Netherlands.

${ }^{2}$ Center of Expertise in Palliative Care, Vu University Medical Center, Amsterdam, the Netherlands.

${ }^{3}$ EMGO Institute for Health and Care Research, VU University Medical Center, Amsterdam, the Netherlands.

${ }^{4}$ NIVEL, Netherlands Institute for Health Services Research, Utrecht, the Netherlands. ${ }^{5}$ Department of Anesthesiology, VU University Medical Center, Amsterdam, the Netherlands. ${ }^{6}$ Department of Anesthesiology, Pain, and Palliative Medicine, Radboud University Nijmegen Medical Center, Nijmegan, the Netherlands.

${ }^{7}$ End-of-Life Care Research Group, Vrije Universiteit Brussel and Ghent University, Brussels, Belgium.

\begin{abstract}
Background: Three important elements of the World Health Organization (WHO) definition of palliative care are: 1) it includes patients who may have cure or life prolongation as treatment aims besides palliative care; 2) it is not exclusively for cancer patients; and 3) it includes attention to the medical, psychological, social, and spiritual needs of the patients and their families. Case managers (nurses with expertise in palliative care) may assist generalist primary care providers in delivery of good palliative care.

Objectives: This study investigates the referral of patients to case managers in primary care with regard to the three elements mentioned: diagnosis, treatment aims, and needs as reflected in reasons given for referral.

Methods: In this cross-sectional survey in primary care among case managers and referrers to case management, case managers completed questionnaires for 687 patients; referrers completed 448 (65\%).

Results: Most patients referred have a combination of treatment aims (69\%). Life expectancy and functional status of patients are lower for those with a treatment aim of palliation. Almost all (96\%) of those referred are cancer
\end{abstract}


Plas, A.G.M. van der, Onwuteaka-Philipsen, B.D., Francke, A.L., Jansen, W.J.J., Vissers, K.C., Deliens, L. Palliative care case managers in primary care: a descriptive study of referrals in relation to treatment aims. Journal of Palliative Medicine: 2015, 18(4), 324-331

patients. A need for psychosocial support is frequently given as a reason for referral (66\%) regardless of treatment aim.

Conclusions: Referrals to case managers reflect two of three elements of the WHO definition. Mainly, patients are referred for support complementary to medical care, and relatively early in their disease trajectory. However, most of those referred are cancer patients. Thus, to fully reflect the definition, broadening the scope to reach other patient groups is important.

\section{INTRODUCTION}

ACCORDING TO THE WORLD HEALth ORGANIZATION (WHO) definition of palliative care, the aim is to improve the quality of life of patients and their families facing the problems associated with life-threatening illness. ${ }^{1}$ This definition has three key elements. First, the definition is not restricted to the terminal stages of disease, but the much broader term of "life-threatening illness" is used. There is an increasing awareness among palliative care experts that there is often no strict boundary between the curative and palliative phase, but rather a shift of emphasis in treatment goals; curative, life prolonging, and/or palliative treatments can co-exist ${ }^{2}$ and may complement each other according to the needs of the patient. Second, palliative care is not only provided to terminally ill cancer patients, but also to those with other lifethreatening diseases and conditions such as chronic obstructive pulmonary disease (COPD), heart failure, and age-related frailty. Third, the definition states that palliative care is aimed at improving the quality of life. This may include physical well-being; psychological, existential, and social factors; and the system surrounding the patient (family, friends). These key elements are not always reflected in actual care provision; palliative care still mostly involves cancer patients in the terminal stages of disease and is often provided with a strong focus on physical symptoms. ${ }^{3-6}$

In the Netherlands, palliative care for home-dwelling patients is mainly provided by generalist care providers, that is, general practitioners (GPs) and home care professionals. ${ }^{7}$ Palliative care case managers, nurses with expertise in palliative care, were introduced to assist GPs and district nurses (DNs) in the delivery of primary palliative care and patients and carers in obtaining the care they prefer. ${ }^{8}$ Case management is a heterogeneous concept of care that consists of assessment, planning, implementing, coordinating, monitoring, and evaluating the options and services required to meet the client's health and service needs. ${ }^{9}$ The patient advocacy model $^{10}$ of case management used in the Netherlands ${ }^{11}$ offers multidimensional coordination of care aimed at quality of care and is distinguished from the interrogative model that is more focused on clinical decision making and emphasises cost-effectiveness.

The question arises of whether the introduction of case management initiatives can facilitate provision of care according to the WHO definition of palliative care. The answer depends, among other things, on which patients are referred to case managers and if so at what stage of their disease trajectory. Therefore, this study examines the referral of patients to palliative care case management with the following research questions: 
Plas, A.G.M. van der, Onwuteaka-Philipsen, B.D., Francke, A.L., Jansen, W.J.J., Vissers, K.C., Deliens, L. Palliative care case managers in primary care: a descriptive study of referrals in relation to treatment aims. Journal of Palliative Medicine: 2015, 18(4), 324-331

1. To what extent do patients referred to a case manager have curative or lifeprolonging treatment aims or palliative treatment aims or a combination of these? And how does this relate to their life expectancy and functional status?

2. What are the patient and care characteristics of those referred to a case manager (including diagnosis), and are there differences in patients with differing treatment aims with regard to patient and care characteristics?

3. What are the reasons patients are referred to a case manager (including how these relate to different domains of palliative care), and are there differences in reasons for referral of patients with differing treatment aims?

\section{METHODS}

\section{Setting}

In the Netherlands, there are 16.6 million inhabitants. Each year, about 77,000 people die of nonacute illnesses and $31 \%$ of these die at home. ${ }^{12}$ GPs see on average three to five palliative care patients a year. ${ }^{13}$ DNs and home support workers who are confronted with end-of-life care see on average 10 palliative care patients a year. ${ }^{14}$ Less than 1\% of GPs and of DNs have had advanced education to specialize in palliative care. ${ }^{15}$ There is a wide range of short courses available on palliative care.

Case management initiatives were identified in a nationwide survey ${ }^{8}$ and 13 of the 20 initiatives identified participated in the current study. Case management is provided by a nurse case manager; he or she visits the patient and their carers at home to discuss options for support. The case manager monitors whether care is delivered according to the patient's and carers' wishes. If patients and their carers wish, informational and psychosocial support is provided by the case manager. The case managers do not provide hands-on nursing care but can be part of a team that does. In the Netherlands, there are case management initiatives for patients with dementia, ${ }^{16}$ but such initiatives are not included in this study.

\section{Procedure}

For this study, when a patient was referred for case management the case manager filled in a questionnaire and sent a questionnaire to the person who referred the patient. The two questionnaires used the same unique identification number. If a patient was entered into the study but no questionnaire from the person referring had been returned, the researcher asked the case manager to send a reminder. Data were gathered from March 2011 until the end of February 2013. Initiatives with many patients could include every second person in the study instead of every patient, for time management reasons. This study is exempt from approval from an ethics committee.

\section{Questionnaires}

The questionnaire filled in by the case manager at the start of case management contained structured questions regarding characteristics of the patient, such as demographic data and questions on diagnosis, prognosis, and treatment aims. 
Plas, A.G.M. van der, Onwuteaka-Philipsen, B.D., Francke, A.L., Jansen, W.J.J., Vissers, K.C., Deliens, L. Palliative care case managers in primary care: a descriptive study of referrals in relation to treatment aims. Journal of Palliative Medicine: 2015, 18(4), 324-331

Treatment aims were measured with the question, "How important are the following treatment aims for the patient at this moment?" for cure, life prolongation, and palliation; answers ranged on a 5-point Likert scale from "not important" (score=1) to “very important” (score=5).

The questionnaire for the person who referred to a case manager had three sections: 1) characteristics of the person who referred; 2) characteristics of patient care in the 30 days before referral; and 3) reasons for referral to and expectations from the case manager. All but one were structured questions; the question on reason for referral was open.

The questionnaires were drafted to study implementation and support provided by the case manager. The questionnaires were piloted on a small sample of respondents to ascertain that the questions were clearly formulated and relevant.

\section{Data analysis}

Patients were grouped according to the treatment aims at the time of referral using data from the questionnaire from the case manager. For cure and life prolongation a combined score was composed in which the highest score on either cure or lifeprolongation prevailed. Three groups were defined:

1. Patients with cure/life prolongation as the main treatment aim (score 3 to 5 ) and for whom palliative care was not a treatment aim (score 1 or 2),

2. Patients with both cure/life prolongation and palliative care as treatment aim (both scores ranging from 3 to 5),

3. Patients with palliation as the main treatment aim (score 3 to 5 ) and for whom cure/life prolongation was not a treatment aim (score 1 or 2 ).

Patients who had either a missing score on the importance of palliation $(n=67)$ or importance of cure/life prolongation $(n=35)$ and those who scored low (score of 1 or 2 ) on all treatment aims $(n=3)$ were excluded (see Fig. 1 for a flow chart of exclusion criteria). For the visualization of these three groups in Table 1, the "trajectory model" of Lynn and Adamson is used. ${ }^{2}$

\section{[FIGURE 1] [TABLE 1]}

The open question on reasons for referral to a case manager was categorized by the first author (AvdP). A sample of answers was also categorized by the second author (BO-P). Categorization was then discussed between AvdP and BO-P. This resulted in "fine-tuning" of categorization choices.

For answering the research question on the relationship between the treatment aims and life expectancy and functional status, data were reported and tested on all three groups with differing treatment aims. For the second and third question, comparisons were made between two groups: "early" (patients with a curative aim and a combination of treatment aims) versus "late" (palliative care treatment aim only). 
Plas, A.G.M. van der, Onwuteaka-Philipsen, B.D., Francke, A.L., Jansen, W.J.J., Vissers, K.C., Deliens, L. Palliative care case managers in primary care: a descriptive study of referrals in relation to treatment aims. Journal of Palliative Medicine: 2015, 18(4), 324-331

Fisher's exact test was calculated for categorical variables except functional status, where Monte Carlo simulation was used, and the student's $t$ test was performed for the one continuous variable (age). To allow for multiple testing, a Bonferroni adjusted $p$ value was chosen for significance (calculated by dividing the value of 0.05 by the number of tests used to answer the research question).

\section{RESULTS}

\section{Response}

A total of 687 patients were included in this study and 448 (65.2\%) questionnaires from referrers were received. Questionnaires from referrers were mostly from professionals ( $n=421 ; 94.0 \%$ ) with a minority from nonprofessionals $(n=27 ; 6.0 \%)$. Professionals were mostly nurses (81.1\%); a further 9.4\% were GPs and the remaining 9.5\% were other professionals (e.g., social workers or medical specialists). Work setting of the professional was hospital for $62.3 \%$ and primary care for $37.7 \%$. Nonprofessional referrers were children of the patient (36.0\%), the partner of the patient (24.0\%), the patient him or herself (20.0\%), or others (e.g., friends or relatives) (20\%).

\section{Patient and care characteristics of patients referred to a case manager}

The life expectancy and functional status of patients referred to a case manager can be seen in Table 1.

Patients with a palliative treatment aim were older (mean age 71 years, standard deviation [SD] 12 years, $p<0.000)$ and more often male $(61 \%, p=0.002)$ than those with combined treatment aims (mean age 65 years, SD 13 years, male 47\%). There are no other differences between the two groups with different treatment aims (see Table 2).

\section{[TABLE 2]}

\section{Reasons for referral to a case manager}

The question, "Why did you refer this patient for case management?" was answered by 440 (98.2\%) referrers. However, 33 answers gave no insight into the reason for requesting case management (e.g., "We refer every patient,” or “terminal cancer”). When disregarding these, 407 (92.5\%) answers remained. Most referrers gave answers that could be allocated to one (46.9\%) or two (40.0\%) categories, but a single open answer was allocated to up to five categories. In Table 3 examples of open answers are given.

\section{[TABLE 3]}

All categories were mentioned in both groups, with psychosocial support being the largest category in both groups; there were no differences between the two groups in treatment aims (see Table 4). 
Plas, A.G.M. van der, Onwuteaka-Philipsen, B.D., Francke, A.L., Jansen, W.J.J., Vissers, K.C., Deliens, L. Palliative care case managers in primary care: a descriptive study of referrals in relation to treatment aims. Journal of Palliative Medicine: 2015, 18(4), 324-331

\section{[TABLE 4]}

\section{DISCUSSION}

The majority of patients referred to a case manager have a combination of treatment aims and are almost exclusively cancer patients. Reasons for referral cover all aspects of palliative care but psychosocial aspects are mentioned most. Patients with treatment focussing on palliative care are more often male and older than those with a combination of treatment aims. There are no differences in reason for referral for patients with a sole palliative care treatment aim compared with patients with combined treatment aims.

\section{Strengths and limitations of this study}

This article is part of a prospective study on case managers and information was gathered at the moment of referral; recall bias therefore will be low. However, of the 20 case management initiatives identified in the Netherlands, 7 did not participate in the current study. Also, this study is conducted within the Dutch health care system where almost all patients are enrolled with a GP, one of the main providers of primary palliative care. Referral to and expectations of case management may be different in health care systems with other characteristics. Furthermore, we do not know why patients are not referred to a case manager as we asked only about those who are referred. Further research is needed to investigate whether case managers actually meets expectations.

\section{Case management is delivered to patients with a combination of treatment aims}

A majority of patients referred to a case manager are receiving a combination of curative/life prolonging and palliative care. The data on life expectancy and functional status suggest that prognosis and functional status govern the balance between treatment aims; both life expectancy and functional status were highest in the group with a sole curative treatment aim, lower in the group with combined aims, and lowest in the group with a sole palliative treatment aim. In our study, most patients were relatively able to function in everyday life, had an estimated life expectancy of more than 3 months, and had curative and/or life-prolonging treatment aims along with palliative care. This suggests that patients are referred to case managers relatively early in their disease trajectory, when discussions on the balance of treatment aims are still relevant and they are still able to engage in discussions on preferred care, including shifts from focus on curative or life-prolonging to palliative treatment aims.

\section{Case management is delivered to cancer patients}

Those referred to case managers are almost exclusively cancer patients. The high proportion of cancer patients in palliative care services is common; in a recent comparison between Canada, the United States, Germany, and England, only the United States had a percentage of $41 \%$ patients in hospice and palliative care with a cancer diagnosis, the other countries had percentages of $90 \%$ or higher. ${ }^{4}$ This can be 
Plas, A.G.M. van der, Onwuteaka-Philipsen, B.D., Francke, A.L., Jansen, W.J.J., Vissers, K.C., Deliens, L. Palliative care case managers in primary care: a descriptive study of referrals in relation to treatment aims. Journal of Palliative Medicine: 2015, 18(4), 324-331

explained by the relatively predictable illness trajectory of cancer. However, we did not find a difference in diagnosis between the earlier and later referred group, whereas one would expect more late referrals with a diagnosis other than cancer given the more unpredictable trajectory. Another cause might be that palliative care originated in cancer care; this may mean that it is easier to establish a working relationship with oncology departments in hospitals so palliative care services receive more referrals of oncology patients. To broaden the scope of palliative care case managers, incorporation of medical and nursing knowledge with regard to noncancer patients, for instance by involving nurses with other specializations (such as heart disease), is needed. Use of tools developed for administrative identification of patients with palliative care needs, specifically including noncancer patients, ${ }^{17,18}$ may provide an aid. For a more general change of culture among care providers, impact of interventions such as Gold Standards Framework ${ }^{19}$ and $\mathrm{PaTz}^{20}$ on knowledge and skills of palliative care provision to noncancer patients should be assessed.

\section{Psychosocial support is mentioned most as reason for referral to case managers}

Whereas all domains of palliative care are mentioned by referrers, the need for psychosocial support is mentioned most. In a study on nurse specialists in palliative care (MacMillan nurses), emotional support was the most common reason for referral. ${ }^{21}$ Psychosocial support transcends disease-specific knowledge. It might be that the patient's need for psychosocial support may be a more suitable pointer for the start of palliative care than life expectancy or diagnosis, because life expectancy is difficult to assess and diagnosis bears the risk of a focus on cancer patients. Existential or spiritual aspects are rarely mentioned explicitly, but acceptance of disease and/or dying is mentioned for $10 \%$ of patients. This resonates with a generally found lack of attention to spiritual issues in palliative care. ${ }^{22}$ On the other hand, it would be unlikely that the need for existential/spiritual care was mentioned as a main reason for referral to a case manager, as referral to an existential/spiritual counsellor would be the more obvious path in that situation.

It appears that patients are referred when the referrer expects that care may be complex or time-consuming, either because the situation at home is considered inadequate or because the referrer considers that the patient and carer may benefit from some psychosocial assistance in dealing with their situation. This seems especially true for referral earlier in the palliative care trajectory for patients with combined treatment aims. This group had less contact with their GP and DN than the group with a sole palliative treatment aim (although not significant). Also, the GPs and DNs may have less time to address psychosocial issues or may find addressing them difficult. ${ }^{23,24}$ It remains to be seen whether case management is the best solution, or whether the GP and DN should be involved earlier.

\section{Conclusion}

Case management referral in primary palliative care fulfils two of the three relevant elements of the WHO definition of palliative care in that it attracts referrals before the terminal stage of the disease and covers all domains of palliative care, with an 
Plas, A.G.M. van der, Onwuteaka-Philipsen, B.D., Francke, A.L., Jansen, W.J.J., Vissers, K.C., Deliens, L. Palliative care case managers in primary care: a descriptive study of referrals in relation to treatment aims. Journal of Palliative Medicine: 2015, 18(4), 324-331

emphasis on psychosocial support, making it complementary to medical care provided in the hospital and by primary care providers. However, those referred to a case manager are almost exclusively cancer patients. Future efforts to improve palliative care case management should focus on broadening the scope to include patients with diagnoses other than cancer.

\section{ACKNOWLEDGMENTS}

The authors wish to thank ZonMw [grant number 80-82100-98-066] for their financial support. The funders had no role in data collection and analysis, selection of respondents, decision to publish, or preparation of the manuscript. Also, we would like to thank Marlies van de Watering for participation and advise in the design and preparation of this study. We thank Anke de Veer and Gwenda Albers for extracting data on home care by district nurses from the VV Panel.

\section{AUthor Disclosure STATEMENT}

No competing financial interests exist.

\section{REFERENCES}

1. C Sepulveda, A Marlin, T Yoshida, et al.: Palliative care: The World Health Organization's global perspective. J Pain Symptom Manage 2002;24:91-96.

2. J Lynn, DM Adamson: Living well at the end of life. Adapting health care to serious chronic illness in old age. Santa Monica, CA: RAND Health, 2003.

3. SA Murray, K Boyd, M Kendall, et al: Dying of lung cancer or cardiac failure: Prospective qualitative interview study of patients and their carers in the community. BMJ 2002;325:929.

4. CA Klinger, D Howell, D Zakus, et al.: Barriers and facilitators to care for the terminally ill: A cross-country case comparison study of Canada, England, Germany, and the United States. Palliat Med 2014;28:111-120.

5. SJ Claessen, AL Francke, Y Engels, et al.: How do GPs identify a need for palliative care in their patients? An interview study. BMC Fam Pract 2013;14:42.

6. N Evans, HR Pasman, AT Vega, et al: End-of-life decisions: A cross-national study of treatment preference discussions and surrogate decision-maker appointments. PLoS ONE 2013;8:e57965.

7. W Schafer, M Kroneman, W Boerma, et al: The Netherlands: health system review. Health Syst Transit 2010;12:v-228.

8. AGM van der Plas, L Deliens, M van de Watering, et al.: Palliative care case management in primary care settings: A nationwide survery. Int J Nurs Stud 2013;50:1504-1512.

9. Commission for Case Manager Certification. Definition of case management.

http://www.ccmcertification.org/secondary.php?section-case-management (Last accessed June 14, 2010.)

10. MJ Long, BS Marshall: What price an additional day of life? A cost-effectiveness study of case management. Am J Manag Care 2000;6:881-886.

11. AGM van der Plas, BD Onwuteaka-Philipsen, $M$ van der Watering, et al.: What is case management in palliative care? An expert panel study. BMC Health Services Research 2012;12:163.

12. LF van der Velden, AL Francke, L Hingstman, et al.: Dying from cancer or other chronic diseases in the Netherlands: Ten-year trends derived from death certificate data. BMC Palliat Care 2009;8:4.

13. MM Groot, MJ Vernooij-Dassen, SC Verhagen, et al: Obstacles to the delivery of primary palliative care as perceived by GPs. Palliat Med 2007;21:697-703. 
Plas, A.G.M. van der, Onwuteaka-Philipsen, B.D., Francke, A.L., Jansen, W.J.J., Vissers, K.C., Deliens, L. Palliative care case managers in primary care: a descriptive study of referrals in relation to treatment aims. Journal of Palliative Medicine: 2015, 18(4), 324-331

14. Nursing Staff Panel. Survey End of Life Care. http://www.nivel.nl/en/panel-nurses-carersVv (Last accessed February 20, 2012.) Utrecht / Amsterdam, NIVEL / EMGO+/ VUmc.

15. IKNL: Palliatieve zorg in beeld [State of affairs in palliative care]. Utrecht: IKNL, 2014.

16. VJ MacNeil, LD Van Mierlo, PM van de Ven, et al: Comparing Dutch case management care models for people with dementia and their caregivers: The design of the COMPAS study. BMC Health Serv Res 2012;12:132.

17. X Gómez-Batiste, M Martínez-Muñoz, C Blay, et al: Identifying patients with chronic conditions in need of palliative care in the general population: Development of the NECPAL tool and preliminary prevalence rates in Catalonia. BMJ Support Palliat Care 2013;3:300308.

18. A O'Callaghan, G Laking, R Frey, et al: Can we predict which hospitalised patients are in their last year of life? A prospective cross-sectional study of the Gold Standards Framework Prognostic Indicator Guidance as a screening tool in the acute hospital setting. Palliat Med 2014;28:1046-1052.

19. KL Shaw, $C$ Clifford, $K$ Thomas, et al.: Improving end-of-life care: A critical review of the gold standards framework in primary care. Palliat Med 2010, 24:317-329.

20. AGM Van der Plas, M Hagens, HRW Pasman, et al: PaTz groups for primary palliative care: Reinventing cooperation between general practitioners and district nurses in palliative care: An evaluation study combining data from focus groups and a questionnaire. BMC FamPract 2014;15:14.

21. J Skilbeck, J Corner, P Bath, et al: Clinical nurse specialists in palliative care. Part 1. A description of the Macmillan Nurse caseload. Palliative Med 2002;16:285-296.

22. N Evans, M Costantini, HR Pasman, et al: End-of-Life Communication: A retrospective survey of representative general practitioner networks in four countries. J Pain Symptom Manage 2014;47:604-619.

23. W Slort, BPM Schweitzer, AH Blankenstein, et al: Perceived barriers and facilitators for general practitioner-patient communication in palliative care: A systematic review. Palliative Med 2011;25:613-629.

24. J Griffiths, G Ewing, M Rogers: "Moving swiftly on." Psychological support provided by district nurses to patients with palliative care needs. Cancer Nurs 2010;33:390-397. 
Plas, A.G.M. van der, Onwuteaka-Philipsen, B.D., Francke, A.L., Jansen, W.J.J., Vissers, K.C. Deliens, L. Palliative care case managers in primary care: a descriptive study of referrals in relation to treatment aims. Journal of Palliative Medicine: 2015, 18(4), 324-331

\section{FIGURE AND TABLES}

FIG. 1. Flow chart of patient exclusion criteria.

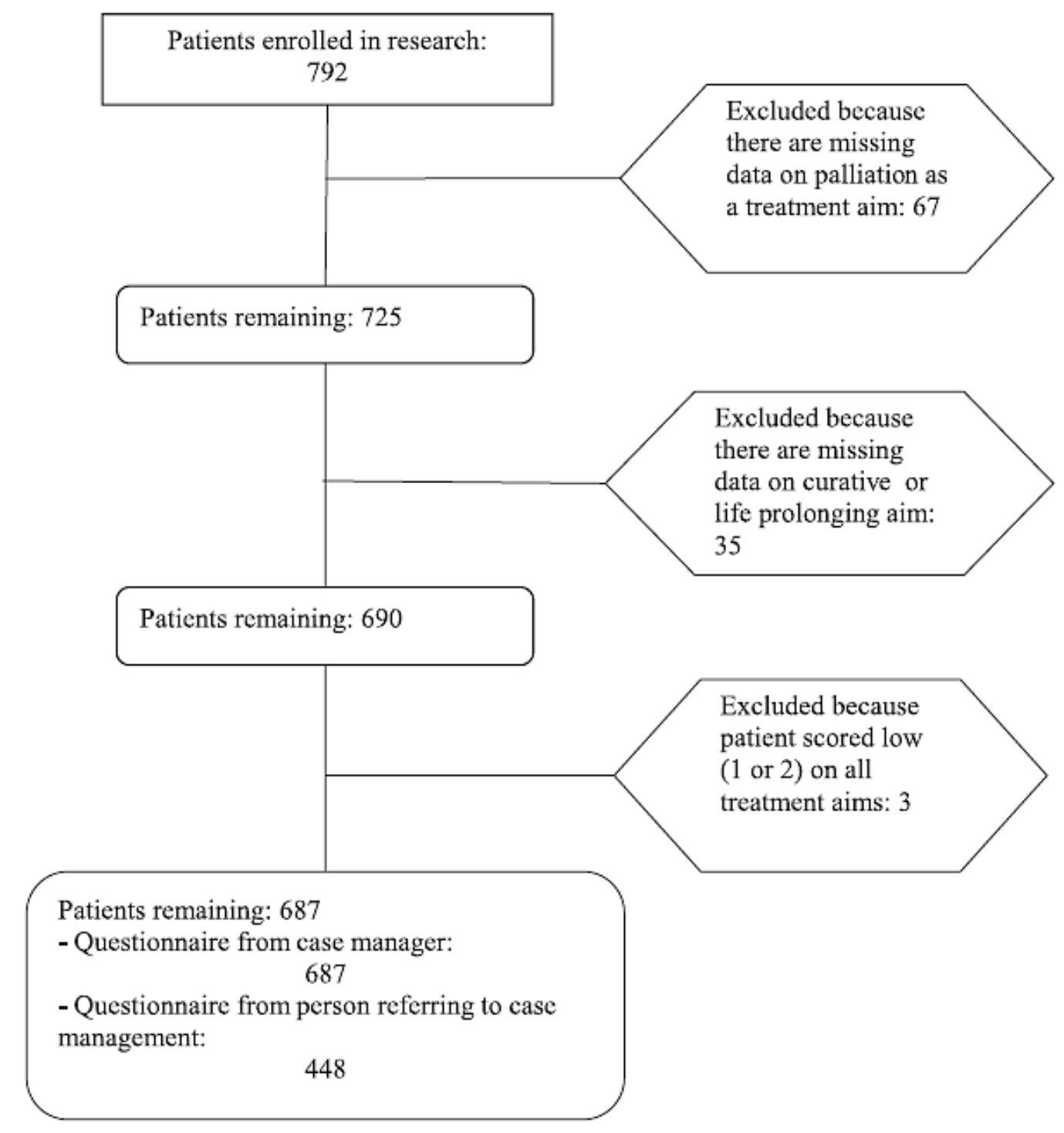


Plas, A.G.M. van der, Onwuteaka-Philipsen, B.D., Francke, A.L., Jansen, W.J.J., Vissers, K.C., Deliens, L. Palliative care case managers in primary care: a descriptive study of referrals in relation to treatment aims. Journal of Palliative Medicine: 2015, 18(4), 324-331

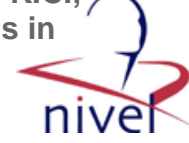

Table 1. Life Expectancy and Functional Status in Relation to Treatment Aims for Patients Referred to a Case Manager in Primary Palliative Care

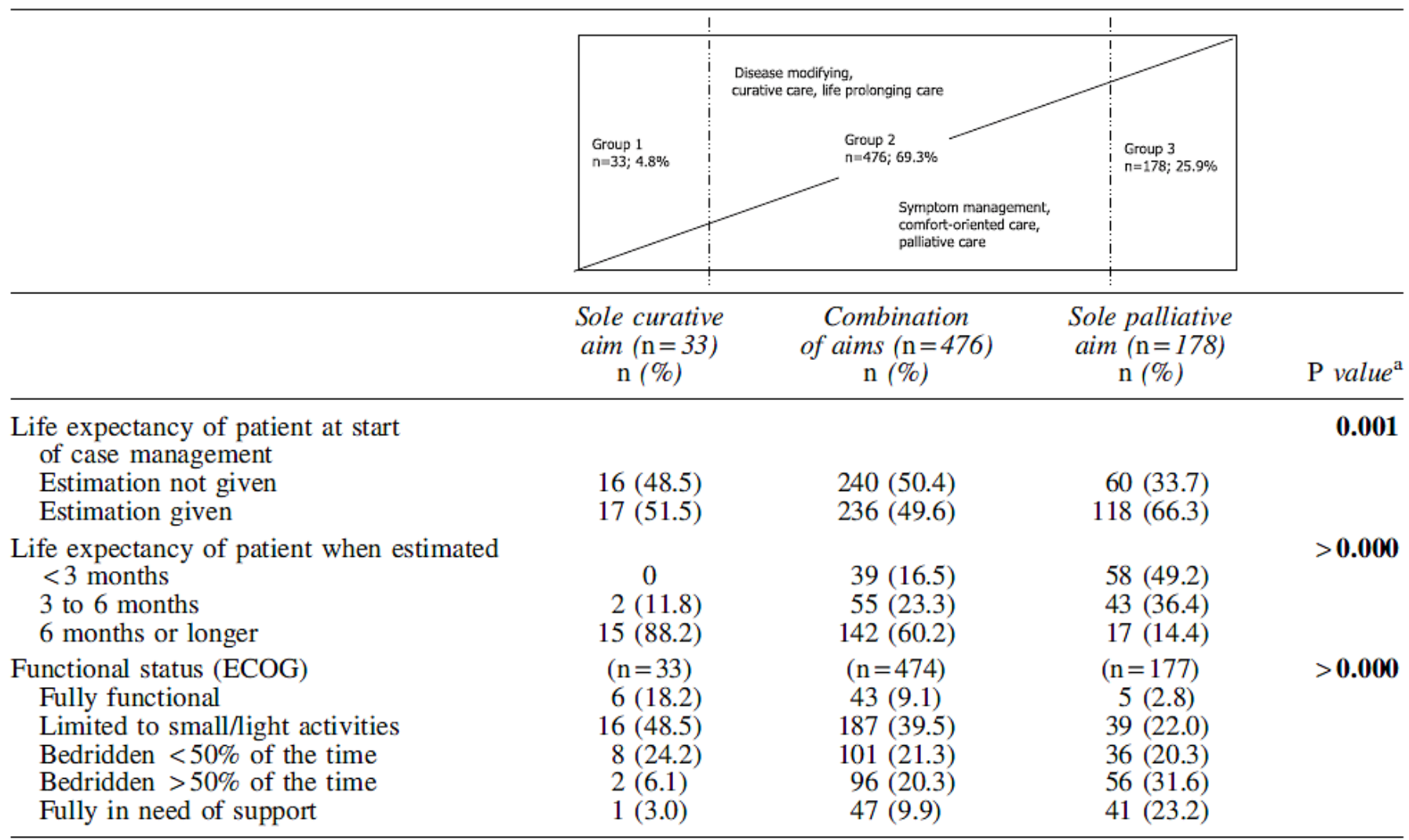

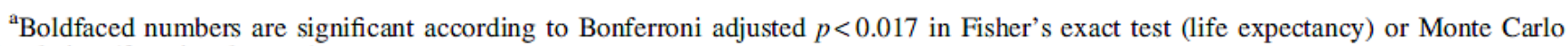
simulation (functional status).

ECOG, Eastern Cooperative Oncology Group. 
Plas, A.G.M. van der, Onwuteaka-Philipsen, B.D., Francke, A.L., Jansen, W.J.J., Vissers, K.C., Deliens, L. Palliative care case managers in primary care: a descriptive study of referrals in relation to treatment aims. Journal of Palliative Medicine: 2015, 18(4), 324-331

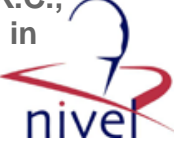

Table 2. Characteristics of Patients in Relation to Treatment aims for Patients Referred to a Case Manager in Primary Palliative Care

\begin{tabular}{|c|c|c|c|c|}
\hline & $\begin{array}{l}\text { Total }^{\mathrm{a}} \\
(\mathrm{n}=687) \\
\mathrm{n}(\%)\end{array}$ & $\begin{array}{c}\text { Combination } \\
\text { of aims }(\mathrm{n}=509) \\
\mathrm{n}(\%)\end{array}$ & $\begin{array}{c}\text { Palliative aim } \\
\text { only }(\mathrm{n}=178) \\
\mathrm{n}(\%)\end{array}$ & $\mathrm{P}$ value $\mathrm{b}^{\mathrm{b}}$ \\
\hline $\begin{array}{l}\text { Main diagnosis } \\
\text { Cancer } \\
\text { Other than cancer }\end{array}$ & $\begin{array}{c}663(96.5) \\
24(3.5)\end{array}$ & $\begin{array}{c}493(96.9) \\
16(3.1)\end{array}$ & $\begin{array}{c}170(95.5) \\
8(4.5)\end{array}$ & 0.476 \\
\hline $\begin{array}{l}\text { Type of cancer }{ }^{\mathrm{c}} \\
\text { Lung } \\
\text { Colon } \\
\text { Breast } \\
\text { Hematological/lymphatic } \\
\text { Prostate } \\
\text { Other }\end{array}$ & $\begin{array}{r}166(25.5) \\
90(13.8) \\
68(10.4) \\
40(6.1) \\
37(5.7) \\
251(38.5)\end{array}$ & $\begin{array}{r}124(25.6) \\
68(14.0) \\
56(11.5) \\
38(7.8) \\
27(5.6) \\
172(35.5)\end{array}$ & $\begin{array}{l}42(25.1) \\
22(13.2) \\
12(7.2) \\
2(1.2) \\
10(6.0) \\
79(47.3)\end{array}$ & 0.003 \\
\hline 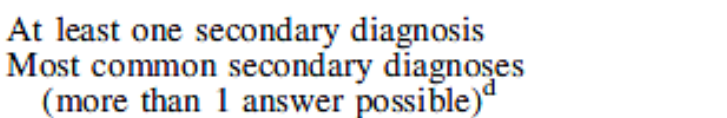 & $283(42.4)$ & $198(39.7)$ & $85(50.3)$ & 0.019 \\
\hline $\begin{array}{l}\text { Heart diseases } \\
\text { Diabetes } \\
\text { Lung diseases }\end{array}$ & $\begin{array}{l}89(31.4) \\
70(24.7) \\
59(20.8)\end{array}$ & $\begin{array}{l}60(30.3) \\
54(27.3) \\
37(18.7)\end{array}$ & $\begin{array}{l}29(34.1) \\
16(18.8) \\
22(25.9)\end{array}$ & $\begin{array}{l}0.577 \\
0.176 \\
0.202\end{array}$ \\
\hline $\begin{array}{l}\text { Service use of patient in } 30 \text { days before referral } \\
\text { to case management (more than } 1 \text { answer poss } \\
\text { General practitioner (GP) } \\
\text { Out of hours service of GP care } \\
\text { District nurse } \\
\text { Specialist (from hospital) } \\
\text { Social worker } \\
\text { Palliative care consultant or consultation team } \\
\text { Spiritual counsellor }\end{array}$ & $\begin{array}{l}298(67.4) \\
38(8.6) \\
86(19.5) \\
366(82.8) \\
46(10.4) \\
32(7.2) \\
23(5.2)\end{array}$ & $\begin{aligned} & 204(63.8) \\
& 22(6.9) \\
& 58(18.1) \\
& 276(86.2) \\
& 41(12.8) \\
& 19(5.9) \\
& 17(5.3)\end{aligned}$ & $\begin{array}{l}94(77.0) \\
16(13.1) \\
28(23.0) \\
90(73.8) \\
5(4.1) \\
13(10.7) \\
6(4.9)\end{array}$ & $\begin{array}{l}0.009 \\
0.056 \\
0.282 \\
0.003 \\
0.008 \\
0.101 \\
1.000\end{array}$ \\
\hline $\begin{array}{l}\text { Residential circumstances } \\
\text { With partner and children } \\
\text { With partner } \\
\text { With children } \\
\text { Alone } \\
\text { Other (e.g., living in an institution or } \\
\text { temporarily living with family) }\end{array}$ & $\begin{array}{r}92(13.5) \\
363(53.4) \\
27(4.0) \\
171(25.1) \\
27(4.0)\end{array}$ & $\begin{array}{r}79(15.6) \\
264(52.2) \\
23(4.5) \\
126(24.9) \\
14(2.8)\end{array}$ & $\begin{array}{c}13(7.5) \\
99(56.9) \\
4(2.3) \\
45(25.9) \\
13(7.5)\end{array}$ & 0.003 \\
\hline $\begin{array}{l}\text { Informal carers (more than } 1 \text { answer possible) } \\
\text { None } \\
\text { Partner } \\
\text { Children } \\
\text { Other family } \\
\text { Other (e.g., friends, neighbors) }\end{array}$ & $\begin{array}{c}5(0.7) \\
415(61.3) \\
459(67.8) \\
210(31.0) \\
233(34.4)\end{array}$ & $\begin{array}{c}3(0.6) \\
316(62.7) \\
332(65.9) \\
163(32.3) \\
188(37.3)\end{array}$ & $\begin{array}{r}2(1.2) \\
99(57.2) \\
127(73.4) \\
47(27.2) \\
45(26.0)\end{array}$ & $\begin{array}{l}0.606 \\
0.207 \\
0.073 \\
0.217 \\
0.007\end{array}$ \\
\hline
\end{tabular}

"Number of missing observations between 0 and 19.

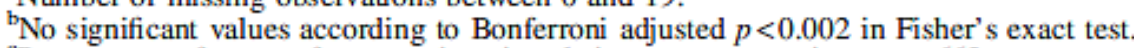

'Percentages of types of cancer given in relation to cancer patients; $n=663$.

${ }^{\mathrm{d}}$ Percentages of types of secondary diagnoses given in relation to patients with at least one secondary diagnosis; $n=283$.

'Lower number of respondents because this question is from the questionnaire the referrers filled in (group with combined aims, $n=320$; group with palliative aims, $n=122$; total $n=442$ ). 
Plas, A.G.M. van der, Onwuteaka-Philipsen, B.D., Francke, A.L., Jansen, W.J.J., Vissers, K.C., Deliens, L. Palliative care case managers in primary care: a descriptive study of referrals in relation to treatment aims. Journal of Palliative Medicine: 2015, 18(4), 324-331

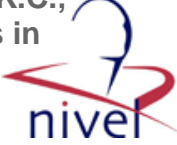

TABle 3. EXAMPLES OF REASONS FOR REFERRAL TO A Case Manager as Reported in an Open Question

Reason given for referral

Support from the general practitioner leaves something to be desired. Husband and wife communicate poorly with each other. Hopefully, the situation at home can be improved with case management. There is not much time left. (Referral of a patient with combination of treatment aims)

The patient was admitted through the emergency department with acute stomach pains. Expected diagnosis was appendicitis or perforated cecum. During surgery an inoperable tumor was found. The patient was very shaken by this unexpected bad news. Went home without knowing "what next." Desperation and tension were high. A lot of questions.

(Referral of a patient with sole palliative care treatment aims)

Bad prognosis. Exhaustive treatment with chemo and radiotherapy. The spouse is overburdened. The patient has a high risk of spinal cord injury, but he insisted on going home; receives probe feeding.

(Referral of a patient with combination of treatment aims)

The capacity of the patient and carer to bear this burden is insufficient. Extra support is necessary in monitoring chemotherapy. Psychosocial support.

(Referral of a patient with combination of treatment aims)

Support for the patient and family-provide information and reassure. Timely identification of problems and proactive care (e.g., pain, tightness of the chest). It is important that the patient and family see a familiar face and have one contact person.

(Referral of a patient with combination of treatment aims)

The husband and wife did not want home care, wanted to be independent as long as possible with help from family and friends. The wife was worried about when to arrange for extra help and how to do this quickly when the situation deteriorates fast.

(Referral of a patient with sole palliative care treatment aims) 
Plas, A.G.M. van der, Onwuteaka-Philipsen, B.D., Francke, A.L., Jansen, W.J.J., Vissers, K.C., Deliens, L. Palliative care case managers in primary care: a descriptive study of referrals in relation to treatment aims. Journal of Palliative Medicine: 2015, 18(4), 324-331

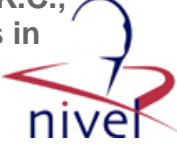

Table 4. Reasons for Referral to a Case Manager in Relation to TREATMEnt Aims, as Reported IN AN OPEN QUeSTION ${ }^{a}$

\begin{tabular}{|c|c|c|c|c|}
\hline & $\begin{array}{l}\text { Total } \\
(\mathrm{n}=407) \\
\mathrm{n}(\%)\end{array}$ & $\begin{array}{l}\text { Combination } \\
\text { of aims }(\mathrm{n}=297) \\
\mathrm{n}(\%)\end{array}$ & $\begin{array}{l}\text { Palliative aim } \\
\text { only }(\mathrm{n}=110) \\
\mathrm{n}(\%)\end{array}$ & $\mathrm{P}$ value $^{\mathrm{b}}$ \\
\hline $\begin{array}{l}\text { Need for psychosocial support (at least one reason } \\
\text { mentioned) }\end{array}$ & $309(75.9)$ & $236(79.5)$ & $73(66.4)$ & 0.009 \\
\hline Support for the patient and carer & $180(44.2)$ & $141(47.5)$ & $39(35.5)$ & 0.033 \\
\hline Acceptance of disease and/or dying & $45(11.1)$ & $32(10.8)$ & $13(11.8)$ & 0.726 \\
\hline Living situation of patient; patient is living alone & $37(9.1)$ & $31(10.4)$ & $6(5.5)$ & 0.173 \\
\hline $\begin{array}{l}\text { Extra attention for carer, prevention of } \\
\text { overburdening the carer }\end{array}$ & $34(8.4)$ & $24(8.1)$ & $10(9.1)$ & 0.840 \\
\hline Living situation of the patient; partner is ill as well & $15(3.7)$ & $11(3.7)$ & 4 (3.6) & 1.000 \\
\hline $\begin{array}{l}\text { Living situation of the patient; relationship } \\
\text { problems }\end{array}$ & $9(2.2)$ & $9(3.0)$ & 0 & 0.121 \\
\hline $\begin{array}{l}\text { Living situation is inadequate for reasons other than } \\
\text { above (e.g., lack of social support) }\end{array}$ & $45(11.1)$ & $40(13.5)$ & $5(4.5)$ & 0.012 \\
\hline Difficulty with accepting medical or nursing care & $12(2.9)$ & $5(1.7)$ & $7(6.4)$ & 0.020 \\
\hline $\begin{array}{l}\text { Patient needs more time for information or support } \\
\text { than can be provided within regular care }\end{array}$ & $8(2.0)$ & $4(1.3)$ & $4(3.6)$ & 0.220 \\
\hline $\begin{array}{l}\text { Need for medical/nursing knowledge (at least one } \\
\text { reason mentioned) }\end{array}$ & $142(34.9)$ & $104(35.0)$ & $38(34.5)$ & 1.000 \\
\hline Anticipating care needs & $65(16.0)$ & $47(15.8)$ & $18(16.4)$ & 0.880 \\
\hline $\begin{array}{l}\text { Monitoring of pharmacotherapy (e.g., oral } \\
\text { chemotherapy or pain medication) }\end{array}$ & $35(8.6)$ & $31(10.4)$ & $4(3.6)$ & 0.029 \\
\hline Specialized palliative care knowledge is needed & $31(7.6)$ & $18(6.1)$ & $13(11.8)$ & 0.060 \\
\hline High symptom burden or comorbidity & $27(6.6)$ & $21(7.1)$ & $6(5.5)$ & 0.659 \\
\hline $\begin{array}{l}\text { Need for information and care coordination (at least } \\
\text { one reason mentioned) }\end{array}$ & $134(32.9)$ & $87(29.3)$ & $47(42.7)$ & 0.013 \\
\hline Practical information for the patient and carer & $62(15.2)$ & $45(15.2)$ & $17(15.5)$ & 1.000 \\
\hline $\begin{array}{l}\text { Guiding the patient to care in accordance with } \\
\text { preferences of the patient/supporting patient in } \\
\text { arranging care as preferred }\end{array}$ & $47(11.5)$ & $26(8.8)$ & $21(19.1)$ & 0.005 \\
\hline Coordination of care & $29(7.1)$ & $16(5.4)$ & $13(11.8)$ & 0.031 \\
\hline $\begin{array}{l}\text { There are problems with care providers (e.g., } \\
\text { difference of opinion between family and GP } \\
\text { on care provision) }\end{array}$ & $7(1.7)$ & $6(2.0)$ & $1(0.9)$ & 0.680 \\
\hline
\end{tabular}

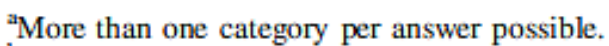

bNo significant values according to Bonferroni adjusted $p<0.003$ in Fisher's exact test.

GP, general practitioner. 